\title{
Femur başı avasküler nekrozunda total kalça artroplastisi
}

\section{Total hip arthroplasty for avascular necrosis of the femoral head}

\author{
Oğuzhan Çimen ${ }^{1}$, Abdullah Demirtaş², İbrahim Azboy ${ }^{3}$ \\ ${ }^{1}$ Koşuyolu Medipol Hastanesi, Ortopedi ve Travmatoloji Kliniği, İstanbul \\ ${ }^{2}$ Isstanbul Medeniyet Üniversitesi Tıp Fakültesi, Ortopedi ve Travmatoloji Anabilim Dalı, İstanbul \\ ${ }^{3}$ Istanbul Medipol Üniversitesi Tıp Fakültesi, Ortopedi ve Travmatoloji Anabilim Dalı, İstanbul
}

\begin{abstract}
Total kalça artroplastisi (TKA) femur başı avasküler nekrozunun ileri evrede olduğu hastalarda endikedir. Artroplasti gerektiren avasküler nekroz hastaları osteoartritli hastalara göre tipik olarak daha gençtir ve daha aktif bir sosyal hayata sahiptir. Son yıllarda cerrahi teknik ve implant tasarımındaki gelişmeler femur başı avasküler nekrozlu hastalarda TKA'nın ömrünü belirgin olarak uzatmıştır. TKA öncesi özellikle kemik kalitesi kötü olan ve eşlik eden sistemik hastalıkları bulunan hastalar, komplikasyon riskini azaltmak amacıyla titizlikle incelenmeli ve gerekli hazırlıklar yapılmalıdır. TKA ileri evre femur başı avasküler nekrozunun tedavisinde başarılı ve etkili bir tedavi yöntemidir.
\end{abstract}

Anahtar sözcükler: femur başı avasküler nekrozu; total kalça artroplastisi; çimentolu; çimentosuz
Total hip arthroplasty (THA) is indicated patients with late stage avascular necrosis (osteonecrosis) of the femoral head. Patients with avascular necrosis of the femoral head that require arthroplasty are typically younger and have more active lifestyle than patients with osteoarthritis. Advances in surgical technique and implant design in recent years have significantly improved the survival of THA in patients with avascular necrosis of the femoral head. Patients should be screened and optimized accordingly to reduce the risk of complication following THA, especially who have poor bone quality and systemic comorbidities. THA is an effective and successful choice for end stage avascular necrosis of the femoral head.

Key words: avascular necrosis of the femoral head; total hip arthroplasty; cemented; cementless

hızlandırdığı polietilen aşınmasına bağlı osteoliz ve periprostetik kemik kaybıdır. Geleneksel metal-polietilen eklemleşmede meydana gelen polietilen aşınmasına bağlı gelişen partiküller osteoliz ve gevşemeye yol açmaktadır. Bunun üstesinden gelmek için aşınmaya daha dayanaklı eklem yüzeyi seçenekleri (seramik-seramik, yüksek oranda çapraz bağlı polietilen) geliştirilmiştir. Cerrahi teknik ve implant tasarımındaki gelişmelerle birlikte avasküler nekrozlu hastalarda yapılan TKA ile primer osteoartritli hastalara yapılanlar karşılaştıııldığında eş değer klinik sonuçlar alınmaktadır. ${ }^{[4]}$

Femur başı avasküler nekrozunda morfolojik olarak trabeküler kemik hacminde, osteoid kalınlığında ve dinamik olarak kalsifikasyon hızında bir azalma mevcuttur. Bu da kansellöz kemiğin zayıf olmasına ve kemik çimentosu kullanımında başarısızlığa sebep olabilmektedir. Femur başı avasküler nekrozlu hastalarda çimentolu TKA sonuçları, diğer nedenlere bağlı yapılan çimentolu TKA sonuçları kadar başarılı değildir. ${ }^{[5]}$ Birinci nesil çimentolama tekniği kullanılarak yapılan

- Illetişim adresi: Op. Dr. Oğuzhan Çimen, Koşuyolu Medipol Hastanesi, Ortopedi ve Travmatoloji Kliniği, 34718 Kadıköy, İstanbul Tel: 0505 - 6452433 e-posta: ozicimen@gmail.com

- Geliş tarihi: 5 Eylül 2020 Kabul tarihi: 29 Ey/ül 2020 
çimentolu TKA sonuçlarında başarı oranı düşmekte ve özellikle asetabular tarafta implant gevşeme prevalansı \%57'ye kadar çıkabilmektedir. ${ }^{[6]}$

Artroplasti sonuçlarını etkileyen nedenlerin başında etiyolojik faktörler gelmektedir. İdiyopatik ve travma sonrası (posttravmatik) avasküler nekroz hastalarının fonksiyonel sonuçlarının, genellikle alkol, steroid ve sistemik hastalığı olanlara göre daha iyi olduğu bildirilmektedir. ${ }^{[7]}$ Kortikosteroidlerin uzun süre kullanılması kemik oluşumunu inhibe etmekte, kemik rezorpsiyonunu artırmakta ve osteoporoza neden olmaktadır. ${ }^{[7]}$ Kortikosteroidler ayrıca yara iyileşmesini bozmakta ve enfeksiyon riskini artırmaktadır. Nitekim 37 çalışmayı içeren bir meta-analizde ( $n=2,470,827)$ kortikosteroid kullanım öyküsünün periprostetik enfeksiyon riskini 1,9 kat artırdığı bildirilmektedir. ${ }^{[8]}$ Başka bir çalışmada, kortikosteroide bağlı avasküler nekroz nedeniyle yapılan TKA sonrası \%17 oranında komplikasyon geliştiği ve \%11 oranında yeniden ameliyat yapıldığı bildirilmektedir. ${ }^{[9]}$

Aşırı alkol kullanımı, özellikle 40 yaşından genç erkek hastalarda travma dışı avasküler nekroz için yaygın risk faktörlerinden biridir. Bu hastalarda eşlik eden hastalıkların daha fazla olduğu, eş zamanlı sigara kullanımı, malnütrisyon ve ameliyat sonrası erken dönemde \%14,5 oranında alkol yoksunluk sendromu bildirilmektedir. ${ }^{[10]} \mathrm{Bu}$ nedenle, artroplasti uygulanacak hastalarda en az 4-6 hafta önce alkolü bırakmaları önerilmektedir. ${ }^{[11]}$ Son yıllarda yapılan çalışmalarda alkole bağlı avasküler nekroz nedeniyle yapılan TKA sonrası orta ve uzun dönem sonuçlar başarılı olarak bildirilmektedir. ${ }^{[10]}$

Böbrek nakli hastalarında femur başı avasküler nekrozu, kortikosteroidlerin ve diğer ilaçların kullanımının bir sonucu olarak ortaya çıkar. Kronik böbrek yetmezliği ve böbrek transplantasyon hastalarında kemik kalitesi belirgin olarak kötüdür. Bu nedenle başlangıçta çimentolu implantlar kullanılmış ve başarısız sonuçlar bildirilmiştir. Yakın zamanda yapılan 797 hastanın dâhil edildiği bir sistemik derlemede hemodiyaliz ve transplant hastalarında TKA yapılması desteklenmektedir. ${ }^{[12]}$ Fakat bu hastalarda revizyon oranı, dislokasyon ve derin enfeksiyon oranının primer osteoartrit nedeniyle yapılan TKA'ya göre daha yüksek oranda görüldüğü vurgulanmaktadır. Çimentolu protezlerde revizyon oranı hemodiyaliz hastalarında ortalama 7,1 yılda \%23, transplant hastalarda 8,3 yılda $\% 15$, çimentosuz protezlerde ise hemodiyaliz hastalarında ortalama 7 yılda \%3,8, transplant hastalarında ise 5,3 yılda \%6,9 olarak saptanmıştır. Bu nedenle hemodiyaliz ve transplant hastalarında çimentosuz TKA önerilmektedir. ${ }^{[12]}$
Orak hücre hastalığının iskelet sistemi bulguları, avasküler nekroz, osteoporoz, patolojik kırıklar ve enfeksiyonlardır. Bu hastalarda, kemik iliği hiperplazisi, korteks ve trabeküler kemiğin incelmesi gibi kemik deformitelerinin yanı sıra femoral kanalda yer yer obliterasyona neden olan sklerotik alanlar sıklıkla görülür. ${ }^{[13,14]} \mathrm{Bu}$ nedenlerle asetabulumun ve femur kanalının hazırlanması sırasında eksentrik oymadan kaçınılmalıdır. Aksi takdirde perforasyon ve kırıklara neden olunabilir. ${ }^{[14]} \mathrm{Bu}$ hastalarda ameliyat öncesi bakım çok önemlidir. Yeterli oksijenizasyon, hidrasyon ve ağrı yönetimi uygulanmaz ise orak hücre krizi gelişebilir. Alloimmunizasyonu azaltmak için lökosit ayıklanmış kan transfüzyonu veya ameliyat öncesi otolog kan hazırlanması önerilmektedir. ${ }^{[15]}$ Ameliyat öncesi kan transfüzyonu, plazmaferez veya exchange transfüzyon, hemoglobin $(\mathrm{Hb}) \mathrm{S}$ seviyelerini azaltmak ve oksijen taşıma kapasitesini artırmak için kullanılabilir. Ameliyat sonrası ilk iki günde $\mathrm{Hb}$ seviyesinin 8-10 g/dL arasında tutulması önerilmektedir. Yakın zamanda yapılan bir sistematik derlemede orak hücreli anemi hastalığına bağlı femur başı avasküler nekrozu için yapılan TKA'da yüksek oranda medikal, ameliyat sırasında ve ameliyat sonrası komplikasyonlar görüldüğü bildirilmektedir. ${ }^{[15]}$ Femoral kırık ve perforasyonların sık olduğu ve özellikle çimentosuz femoral stemlerin kullanıldığı olgularda ameliyat sırasında femoral kırık riskinin daha yüksek olduğu bildirilmektedir. Bu hastalarda yapılan TKA'nın en önemli başarısızlık nedeni enfeksiyon ve aseptik gevşemedir. Aseptik gevşeme femurdan ziyade asetabular tarafta daha fazla görülmektedir. En iyi tespit metodu ile ilgili kesin bir sonuç çıkarılamayacağı, çimentolu implantlarda revizyon oranlarının daha yüksek olduğu (çimentolu \%24, çimentosuz \%10) ve çimentosuz implantlarda ise ameliyat sırasında komplikasyonların daha yüksek olduğu bildirilmektedir. ${ }^{[15]}$

Avasküler nekrozda birinci ve ikinci kuşak çimentolama teknikleri kullanılarak yapılan TKA'da yüksek oranda mekanik yetmezlik ve revizyon oranları bildirilmiştir. ${ }^{[16]}$ Yedi ile on dört yıllık takiplerde mekanik yetmezlik oranları $\% 9,1-48$, revizyon oranları ise \%13-28 olarak bildirilmektedir. ${ }^{[16]}$ Buna karşılık üçüncü kuşak çimentolama tekniğinin, özellikle femoral tarafta sağkalımı artırdığı gösterilmiştir. Çimentolu femoral stemler yaşlı ve medüller kanaIı belirgin genişlemiş hastalar için idealdir. Kim ve ark. ${ }^{[17]}$, avasküler nekroz nedeniyle TKA yaptıkları 94 hastanın (148 kalça) ortalama 17,3 yıl takibinde hem proksimal poroz kaplı çimentosuz femoral stemler (98 kalça) hem de çimentolu femoral stemler (50 kalça, asetabular komponentler çimentosuz) için \%98 sağkalım oranı ile oldukça başarılı sonuç bildirmişlerdir. Benzer bir çalışmada Simon ve ark. ${ }^{[18]}$, avasküler 
nekroz nedeniyle TKA yaptıkları 34 kalçanın ortalama 10,9 yıllık takibinde, çimentolu femoral komponentte \%100 sağkalım bildirmekle birlikte, üçüncü kuşak çimentolama tekniği kullanılsa bile asetabular komponentin çimentolu uygulanması sonrası radyolojik olarak \%42 oranında gevşeme görüldüğünü, ortalama 11 yıllık takipte $\% 7$ revizyon yapıldığını bildirmiş̧ir. ${ }^{[19]}$

Çimentolu protez sistemlerinin uygulandığı hastaların uzun süreli takiplerinde aseptik gevşeme ve kemik erozyonu gibi geç komplikasyonların yüksek olması nedeniyle, genç ve özellikle aktif hastalarda biyolojik tespit prensibi ile geliştirilen çimentosuz protezler daha sık kullanılmaya başlanmıştır. Yeni nesil çimentosuz protezlerin uygun cerrahi tekniklerle uygulanmasıyla birlikte, avasküler nekrozlu genç ve aktif hastalarda mükemmel sonuçlar bildirilmektedir (Tablo 1). Hartley ve ark.[20] metal baş ve geleneksel polietilen kullanılarak yaptıkları çimentosuz TKA sonrası 10 yıllık takipte hiç bir hastada femoral revizyon yapmadıklarını, Kim ve ark. ${ }^{[21]}$ elli yaş altındaki hastalarda metal baş ve geleneksel polietilen kullanılarak yaptıkları çimentosuz TKA'da 18. yılda asetabular komponentte $\% 84$, femoral komponentte ise \%96 implant sağkalımı bildirmektedir.

Son yıllarda metafizer kemik stoğun korunduğu kısa femoral stemlerle başarılı sonuçlar bildirilmektedir. ${ }^{[22]}$ Fakat öncesinde manyetik rezonans (MR) ile osteonekrotik lezyonun metafize ulaşmadığı görülmelidir. ${ }^{[23]}$
TKA'da yüksek çapraz bağlı polietilen (HXLPE) kullanımı, geleneksel polietilene kıyasla \%40'a varan azalmış aşınma oranı nedeniyle ön plana çıkmıştır. 60 yaşın altındaki hastalarda HXLPE, yılda ortalama 0,02-0,04 $\mathrm{mm}$ aşınma oranına sahiptir. Geleneksel polietilendeki aşınma ile karşılaştırıldığında (yılda ortalama 0,1-0,2 mm) uzun dönem sağkalım için önemli ölçüde avantaj sağlamaktadır. ${ }^{[16]}$ Genç hastalarda HXLPE kullanılarak yapılan TKA çalışmalarının çoğunda osteoliz görülmediği bildirilmekle birlikte ${ }^{[24-27]}$, ortalama 7,2 yıllık takipte $\% 2$, beş yıllık takipte \%8 oranında osteoliz görüldügüüü bildiren çalışmalar bulunmaktadır (Tablo 2). ${ }^{[28,29]}$ Avasküler nekroz nedeniyle HXLPE kullanarak yapılan TKA'da uzun dönem takipte mükemmel klinik ve radyolojik sonuçlar bildirilmektedir. ${ }^{[24,25]}$ Avasküler nekroz nedeniyle TKA yapılan 413 hasta (461 kalça) ve osteoartrit nedeniyle TKA yapılan 427 hastanın (461 kalça) 15 yıllık takibinde avasküler nekrozlu grupta $\% 6,6$, osteoartritli grupta $\% 4,5$ oranında revizyon oranı rapor edilmiştir ( $p=0,09)$.

Polietilen aşınması ve bunun sonucunda gelişen osteoliz TKA'da başarısız sonuçlara neden olmuş ve bu nedenle aşınmaya daha dayanıklı seramik-HXLPE ve seramik-seramik gibi yüzey materyalleri geliştirilmiştir. Bunların içinde seramik-seramik eklemleşme aşınmaya karşı en dirençli olanıdır. Bununla birlikte, seramik kırılması ve gıcırtı sesi istenmeyen komplikasyonlardır. Illk dönem seramiklerin saflıklarının düşük olması ve partiküler özelliklerinin yüksek olması nedeniyle kırılma riskleri önemli bir sorundu. Seramik üretimindeki

Tablo 1. Femur başı avasküler nekrozunda tespit yöntemine göre TKA sonuçları

\begin{tabular}{|c|c|c|c|c|c|c|}
\hline Çalışma & Tespit yöntemi & $\begin{array}{c}\text { Kalça } \\
(n)\end{array}$ & $\begin{array}{l}\text { Ort. yaş } \\
(y \mathrm{l})\end{array}$ & $\begin{array}{l}\text { Ort. takip } \\
\text { süresi (yıl) }\end{array}$ & Sağkalım (\%) & Başarısızlık nedeni \\
\hline Fyda ve ark. ${ }^{[5]}$ & $\begin{array}{l}\text { Birinci nesil çimentolama (16 kalça) } \\
\text { Íkinci nesil çimentolama (32 kalça) }\end{array}$ & 48 & 54,6 & 14,5 & $87\left(10 . y_{11}\right)$ & $\begin{array}{l}\text { Femoral gevşeme \%6,5 } \\
\text { Asetabular gevşeme \%13 } \\
\text { Sepsis \%2,9 } \\
\text { Dislokasyon \%2,9 }\end{array}$ \\
\hline Kim ve ark. ${ }^{[17]}$ & $\begin{array}{l}\text { Hibrid (üçüncü nesil çimentolama) } \\
\text { Çimentosuz protez }\end{array}$ & $\begin{array}{l}48 \\
94\end{array}$ & 47,3 & 17,3 & $\begin{array}{l}98 \text { femoral } \\
83 \text { asetabulum } \\
\text { (Hibrid) } \\
85 \text { asetabulum } \\
\text { (çimentosuz) }\end{array}$ & $\begin{array}{l}\text { Enfeksiyon \%2 (çimentolu) } \\
\text { Kırık \%2 (çimentosuz grup) } \\
\text { İnsert aşınması ve osteoliz } \\
\text { nedeniyle asetabular } \\
\text { revizyon \%15 }\end{array}$ \\
\hline Simon ve ark. ${ }^{[18]}$ & $\begin{array}{l}\text { Hibrid ( } 28 \text { kalça) } \\
\text { Çimentolu (6) (üçüncü nesil çimentolama) }\end{array}$ & 34 & 28,3 & 10,9 & $\begin{array}{l}100 \text { (Femoral) } \\
90 \text { (Asetabular) }\end{array}$ & $\begin{array}{l}\text { Asetabular gevşeme } \% 15 \\
\text { Femoral gevşeme } \% 0\end{array}$ \\
\hline Min ve ark. ${ }^{[24]}$ & Çimentosuz (HXLPE-Metal baş) & 85 & 42 & 13,5 & 100 & Revizyon yok \\
\hline Kim ve ark. ${ }^{[27]}$ & Çimentosuz (CoHXLPE) & 60 & 28,3 & 10,8 & 100 & Revizyon yok \\
\hline
\end{tabular}

HXLPE, yüksek çapraz bağlı polietilen; CoHXLPE, seramik-yüksek çapraz bağlı polietilen 
Tablo 2. Femur başı avasküler nekrozunda eklemleşme tipine göre TKA sonuçları

\begin{tabular}{|c|c|c|c|c|c|c|}
\hline Çalışma & Eklemleşme tipi & $\begin{array}{l}\text { Kalça } \\
(n)\end{array}$ & $\begin{array}{l}\text { Ort. yaş } \\
\quad(y ı l)\end{array}$ & $\begin{array}{l}\text { Ort. takip } \\
\text { süresi }(y \mathrm{l})\end{array}$ & $\begin{array}{c}\text { Osteoliz } \\
(\%)\end{array}$ & Sağkalım (\%) \\
\hline Min ve ark. ${ }^{[24]}$ & HXLPE-Metal baş & 85 & 42 & 13,5 & 0 & 100 \\
\hline Feng ve ark. ${ }^{[26]}$ & $\begin{array}{l}\mathrm{CoC} \\
\mathrm{CoHXLPE}\end{array}$ & $\begin{array}{l}93 \\
77\end{array}$ & $\begin{array}{l}51 \\
59\end{array}$ & $\begin{array}{l}6,9 \\
7,2\end{array}$ & $\begin{array}{l}0 \\
0\end{array}$ & -- \\
\hline Kim ve ark. ${ }^{[27]}$ & CoHXLPE & 60 & 28,3 & 10,8 & 0 & 100 \\
\hline Mall ve ark. ${ }^{[28]}$ & $\begin{array}{l}\text { Geleneksel PE-metal baş } \\
\text { HXLPE-metal baş }\end{array}$ & $\begin{array}{l}50 \\
48\end{array}$ & $\begin{array}{l}43,2 \\
46,5\end{array}$ & $\begin{array}{l}8,29 \\
6,02\end{array}$ & $\begin{array}{c}24 \\
2\end{array}$ & -- \\
\hline Leung ve ark. ${ }^{[29]}$ & $\begin{array}{l}\text { Geleneksel PE-metal baş } \\
\text { HXLPE-metal baş }\end{array}$ & $\begin{array}{l}40 \\
36\end{array}$ & $\begin{array}{l}61,5 \\
60,5\end{array}$ & $\begin{array}{l}6,1 \\
6,1\end{array}$ & $\begin{array}{c}28 \\
8\end{array}$ & -- \\
\hline Kim ve ark. ${ }^{[30]}$ & Biolox delta seramik & 334 & 48,2 & 13,1 & 0 & $\begin{array}{l}99,7 \text { (asetabular) } \\
99,3 \text { (femoral) }\end{array}$ \\
\hline Lee ve ark. ${ }^{[31]}$ & Biolox delta seramik & 252 & 49,7 & 5,5 & 0 & 99 \\
\hline Kim ve ark. ${ }^{[32]}$ & Biolox-forte seramik & 1131 (\%53 avasküler nekroz) & 52,9 & 18,8 & 0 & $\begin{array}{l}99,7 \text { (asetabular) } \\
100 \text { (femoral) }\end{array}$ \\
\hline Baek ve Kim ${ }^{[33]}$ & Biolox forte seramik & 71 & 39,1 & 7,1 & 0 & 100 \\
\hline
\end{tabular}

PE, Polietilen; HXLPE, yüksek çapraz bağlı polietilen; OA, osteoartrit; Co-C, seramik-seramik; CoHXLPE, seramik-yüksek çapraz bağlı polietilen.

son gelişmelerle birlikte, seramik implantların yüksek saflık ve yoğunluğa sahip olması ve sertlik, eğilme mukavemeti ve patlama mukavemeti gibi uygun mekanik özelliklerin geliştirilmesi ile kırık riski çok azalmıştır. ${ }^{[30]}$ Femur başı avasküler nekrozlu hastalarda seramik-seramik implantların sağkalım oranı, implant tasarımına bağlı olarak 10-15 yıllık takipte \%85 ile \%100 arasında değişmektedir. ${ }^{[16]}$ Son yıllarda yapılan çalışmalarda üçüncü ve dördüncü nesil seramik-seramik kullanılan TKA'latda oldukça başarılı sonuçlar bildirilmektedir (Şekil 1 ve 2) (Tablo 2). ${ }^{[30,33]}$ Kim ve ark. ${ }^{[31]}, 334$ kalçanın 7,8 yıllık takibinde hiçbir hastada seramik kırığı
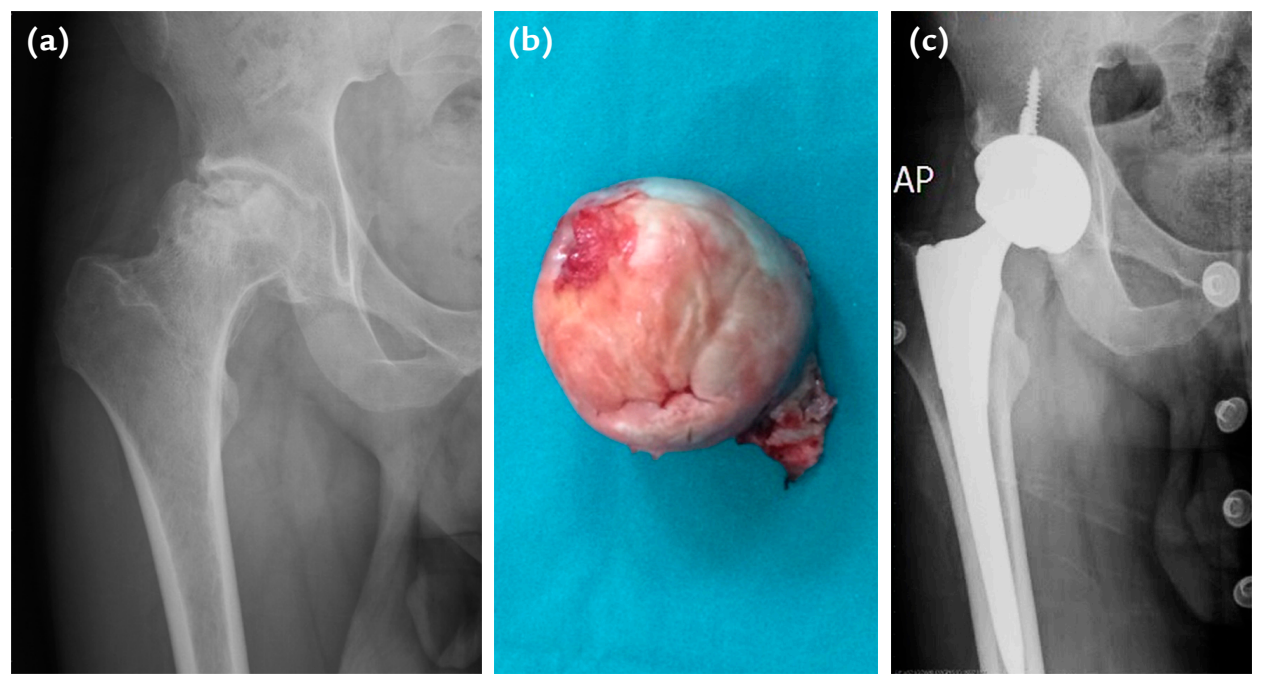

Şekil 1. a-c. Alopesi nedeniyle kortikosteroid kullanımına bağlı sağ femur başı avasküler nekrozu gelişen 27 yaşında erkek hastanın; ameliyat öncesi radyografısi (a), femur başındaki çökme (b) ve seramik üzeri seramik çimentosuz total kalça protezi ameliyatının 6. yılına ait radyografisi (c) izlenmektedir. 

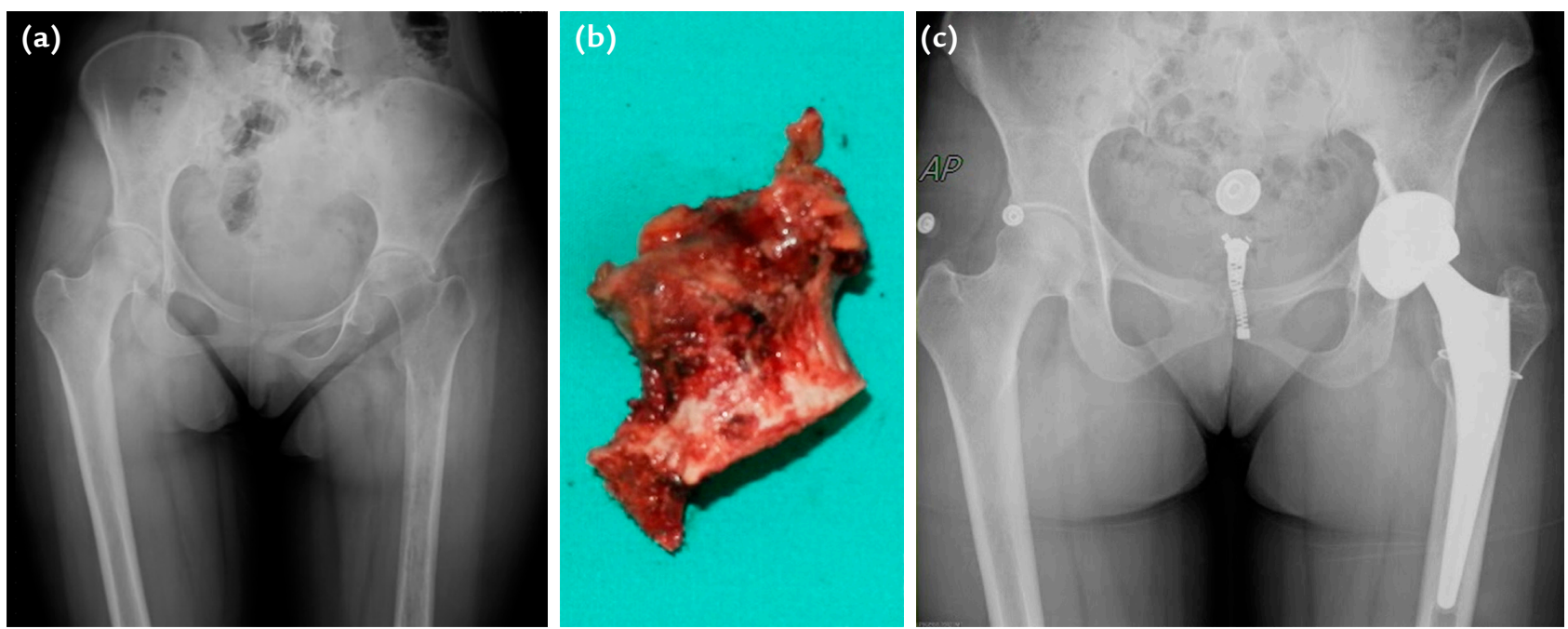

Şekil 2. a-c. Aplastik anemi nedeniyle kortikosteroid kullanımına bağlı sol femur başı avasküler nekrozu gelişen 21 yaşında kadın hastanın; ameliyat öncesi radyografisi (a), femur başında meydana gelen çökme (b) ve seramik üzeri seramik çimentosuz total kalça protezi ameliyatının 7. yılına ait radyografisi (c) izlenmektedir.

görmediklerini (\%99,7 sağkalım), Hamilton ve ark. ${ }^{[34]}$ ise 345 kalçanın ortalama 5,3 yıl takibinde iki hastada seramik insert kırılması (\%97,3 sağkalım) gördüklerini bildirmişlerdir.

Sonuç olarak, modern implant ve cerrahi teknik kullanılması ile birlikte femur başı avasküler nekrozu sonrası yapılan TKA'nın uzun dönem sonuçları, primer osteoartrit nedeniyle yapılan TKA kadar başarılıdır. Ancak, kemik kalitesi ve aktivite düzeyininin uzun dönem sonuçlar üzerinde etkili olduğu bilinmelidir. Gaucher, orak hücreli anemi ve böbrek transplantlı hastalarda gevşeme oranlarının yüksek olduğu akılda tutulmalıdır. Bu nedenle, ameliyat öncesinde hastaların etiyolojik nedenleri göz önünde bulundurularak hazırlıklar titizlikle yapılmalıdır. İmplant seçimi ve tespit yönteminin belirlenmesinde kemik kalitesi ve geometrisi göz önünde bulundurulmalıdır.

\section{KAYNAKLAR}

1. Swarup I, Lee YY, Movilla P, Figgie MP. Common factors associated with osteonecrosis of the femoral head in young patients requiring total hip arthroplasty. Hip Int 2015;25(3):232-6. Crossref

2. Mont MA, Jones LC, Hungerford DS. Nontraumatic osteonecrosis of the femoral head: ten years later. J Bone Joint Surg Am 2006;88(5):1117-32. Crossref

3. Kaushik AP, Das A, Cui Q. Osteonecrosis of the femoral head: an update in year 2012. World J Orthop 2012;3(5):49-57. Crossref

4. Rinjen W, Lamejin N, Schreurs BW, Gardeniers JWM. Total hip arthroplasty after failed treatment for osteonecrosis of the femoral head. Orthop Clin North Am 2009;40(2):291-8. Crossref
5. Fyda TM, Callaghan JJ, Olejniczak J, Johnston RC. Minimum ten-year follow-up of cemented total hip replacement in patients with osteonecrosis of the femoral head. lowa Orthop J 2002;22:8-19. https://www.ncbi.nlm.nih.gov/ pmc/articles/PMC1888371/

6. Chandler HP, Reinneck FT, Wixson RL, McCarthyJC. Total hip replacement in patients younger than thirty years old: a five year follow up study. J Bone Joint Surg Am 1981;63(9):142634. Crossref

7. Singh JA, Chen J, Inacio MC, Namba RS, Paxton EW. An underlying diagnosis of osteonecrosis of bone is associated with worse outcomes than osteoarthritis after total hip arthroplasty. BMC Musculoskelet Disord 2017;18(1):8. Crossref

8. Resende VAC, Neto AC, Nunes C, Andrade R, EspregueiraMendes J, Lopes S Higher age, female gender, osteoarthritis and blood transfusion protect against periprosthetic joint infection in total hip or knee arthroplasties: A systematic review and meta-analysis. Knee Surg Sports Traumatol Arthrosc 2018. Crossref

9. Rahman WA, Garbuz DS, Masri BA. Total hip arthroplasty in steroid-induced osteonecrosis: early functional and radiological outcomes. Can J Surg 2013;56(1):41-6. Crossref

10. Ponzio DY, Pitta M, Carroll KM, Alexiades M. Hip arthroplasty for osteonecrosis of the femoral head secondary to alcohol abuse. Arthroplast Today 2018:11;5(2):172-5. Crossref

11. Tonnesen $\mathrm{H}$, Kehlet $\mathrm{H}$. Preoperative alcoholism and postoperative morbidity. BrJ Surg 1999;86(7):869-74. Crossref

12. Popat R, Ali AM, Holloway IP, Sarraf KM, Hanna SA. Outcomes of total hip arthroplasty in haemodialysis and renal transplant patients: systematic review. Hip Int 2019;1120700019877835. Crossref

13. Vanderhave KL, Perkins CA, Scannell B, Brighton BK. Orthopaedic manifestations of sickle cell disease. J Am Acad Orthop Surg 2018;26:94-101. Crossref

14. Ilyas I, Alrumaih HA, Rabbani S. Non-cemented total hip arthroplasty in sickle-cell disease: long-term results. J Arthroplasty 2018;33:477-81. Crossref 
15. Kenanidis E, Kapriniotis K, Anagnostis P, Potoupnis M, Christofilopoulos P, Tsiridis E. Total hip arthroplasty in sickle cell disease: a systematic review. EFORT Open Rev 2020:2;5(3):180-8. Crossref

16. Waewsawangwong W, Ruchiwit P, Huddleston JI, Goodman SB. Hip arthroplasty for treatment of advanced osteonecrosis: comprehensive review of implant options, outcomes and complications. Orthop Res Rev 2016:8:13-29. Crossref

17. Kim YH, Kim JS, Park JW, Joo JH. Contemporary total hip arthroplasty with and without cement in patients with osteonecrosis of the femoral head: a concise follow-up, at an average of seventeen years, of a previous report. J Bone Joint Surg Am 2011:5;93(19):1806-10. Crossref

18. Simon JP, Berger P, Bellemans J. Total hip arthroplasty in patients less than 40 years old with avascular necrosis of the femoral head. A 5 to 19-year follow-up study. Acta Orthop Belg 2011;77:53-60. https://pubmed.ncbi.nlm.nih. gov/21473446/

19. Mulroy RD, Harris WH. The effect of improved cementing techniques on component loosening in total hip replacement: an 11-year radiographic review. J Bone Joint Surg Br 1990;72$\mathrm{B}(5): 757-60$. Crossref

20. Hartley WT, McAuley JP, Culpepper WJ, Engh CA Jr, Engh CA Sr. Osteonecrosis of the femoral head treated with cementless total hip arthroplasty. J Bone Joint Surg Am 2000;82(10):1408-13. Crossref

21. Kim YH, Kim JS, Park JW, Joo JH. Comparison of total hip replacement with and without cement in patients younger than 50 years of age: the results at 18 years. J Bone Joint Surg $\mathrm{Br}$ 2011;93(4):449-55. Crossref

22. Kim YH, Park JW. Ultra-short anatomic uncemented femoral stem and ceramic-on-ceramic bearing in patients with idiopathic or ethanol-induced femoral headosteonecrosis. J Arthroplasty 2020;35(1):212-8. Crossref

23. Floerkemeier T, Budde S, Gronewold J, Radtke K, Ettinger M, Windhagen $\mathrm{H}$, von Lewinski G. Short-stem hip arthroplasty in osteonecrosis of the femoral head. Arch Orthop Trauma Surg 2015;135(5):715-22. Crossref

24. Min BW, Cho CH, Son ES, Lee KJ, Lee SW, Song KS. Highly Cross-Linked Polyethylene in Total Hip Arthroplasty in Patients Younger Than 50 Years With Osteonecrosis of the Femoral Head: A Minimum of 10 Years of Follow-Up. J Arthroplasty 2020;35(3):805-10. Crossref
25. Hart A, Janz V, Trousdale RT, Sierra RJ, Berry DJ, Abdel MP. Long-Term Survivorship of Total Hip Arthroplasty with Highly Cross-Linked Polyethylene for Osteonecrosis. J Bone Joint Surg Am 2019;101(17):1563-8. Crossref

26. Feng B, Ren Y, Cao S, Lin J, Jin J, Qian W, Weng X. Comparison of ceramic-on-ceramic bearing vs ceramic-on-highly crosslinked polyethylene-bearing surfaces in total hip arthroplasty for avascular necrosis of femoral head: a prospective cohort study with a mid-term follow-up. J Orthop Surg Res 2019:27;14(1):388. Crossref

27. Kim YH, Park JW, Patel C, Kim DY. Polyethylene wear and osteolysis after cementless total hip arthroplasty with alumina-on-highly cross-linked polyethylene bearings in patients younger than thirty years of age. J Bone Joint Surg Am 2013;95(12):1088-93. Crossref

28. Mall NA, Nunley RM, Zhu JJ, Maloney WJ, Barrack RL, Clohisy JC. The incidence of acetabular osteolysis in young patients with conventional versus highly crosslinked polyethylene. Clin Orthop Relat Res 2011;469(2):372-81. Crossref

29. Leung SB, Egawa H, Stepniewski A, Beykirch S, Engh Jr CA, Engh CA. Incidence and volume of pelvic osteolysis at early follow-up with highly cross-linked and noncross-linked polyethylene. J Arthroplasty 2007;22(6):134-9. Crossref

30. Lee YK, Ha YC, Yoo JI, Jo WL, Kim KC, Koo KH. Mid-term results of the BIOLOX delta ceramic-on-ceramic total hip arthroplasty. Bone Joint J 2017;99-B(6):741-8. Crossref

31. Kim YH, Park JW, Kim JS. Alumina delta-on-alumina delta bearing in cementless total hip arthroplasty in patients aged $<50$ years. J Arthroplasty 2017;32(3):1048-53. Crossref

32. Kim YH, Park JW, Kim JS. Long-Term Results of ThirdGeneration Ceramic-on-Ceramic Bearing Cementless Total Hip Arthroplasty in Young Patients. J Arthroplasty 2016;31(11):2520-4. Crossref

33. Baek SH, Kim SY. Cementless total hip arthroplasty with alumina bearings in patients younger than fifty with femoral head osteonecrosis. J Bone Joint Surg Am 2008;90(6):131420. Crossref

34. Hamilton WG, McAuley JP, Blumenfeld TJ, Lesko JP, Himden $\mathrm{SE}$, Dennis DA. Midterm results of delta ceramic-on-ceramic total hip arthroplasty. J Arthroplasty 2015;30(9):110-5. Crossref 